\title{
Research on Cultivation of Ethnic Minorities IT Talents in Nationalities Universities
}

\author{
Shuang Liu \\ School of Computer Science \& Engineering, Dalian Nationalities University, Dalian, Liaoning, China \\ Email: dlnuliushuang@126.com \\ Peng Chen \\ Department of Computer Science \& Technology, Dalian Neusoft University of Information, Dalian, Liaoning, China \\ Email: chenpeng@neusoft.edu.cn
}

\begin{abstract}
To promote cultural and information undertakings of the ethnic minorities such as digital publication and network governance, a series of experience training programs for nationalities universities are established to cultivate high-quality IT technology talents. Here, Dalian Nationalities University is taken as an example. These training programs adopted a so called "four-phrases, five capabilities" training method. That is, four phrases consist of professional quality training, professional basic theory strengthening, job skills training and job practice, centering on training five capabilities of professional morality, software programming fundamentals, language competence, software engineering and project practice. Based on the training method, one well-rounded and multiple perspective assessment method are put forward. This assessment system integrated academic knowledge evaluation and professional competence assessment, adopting various forms such as coding, competition, discussion, peer review online and deliverables exhibition. These practice training courses break through the knowledge barrier and put emphasis on professional competence cultivation, which improves teaching quality and assesses learning effects objectively and fairly during teaching process.
\end{abstract}

Index Terms-Ethnic Minorities IT Talents, Nationalities University, Experience Training Program, Assessment, Professional Competence.

\section{INTRODUCTION}

With rapid development of IT technology, all industries especially minority areas demand more and more IT talents in information industry. Take Inner Mongolia as an example, number for information talents in library, network, broadcast television is at least 6000 each year. Only in Hulunbeier, a further 600 talents is estimated in fields of copyright protection, network information service, digital publication and broadcast or film production each year. China is a large developing country with a population of 1.3 billion and 56 ethnic groups. The special conditions in China have dictated the country's unbalanced development, especially in minority areas. According some statistical data, there is an increasing gap between ethnic minority areas and coastal open areas in information development.

To quicken the information industry development of minority communities and minority areas and overcome the difficulties and solve the problems in the minority areas hinges on development, IT talents of information industry play an irreplaceable important role. How to cultivate ethnic minorities IT talents in ethnic higher education for promoting the information development of the minority areas is the key issue.

Some researchers have done related works. For example, Liu discussed how to adopt employmentoriented experience training program to improve employment competence of undergraduates in [1] and how to apply bilingual teaching on employment-oriented IT experience training program in nationalities universities in [2].

But due to shortage of project experiences, many undergraduates with computer major cannot meet qualification of practical requirements of high-tech software companies especially for minority industry [3-5] How to keep pace with technology development and cultivate compound ethnic minorities IT talents of software development is the main focus of our experience training programs beginning from 2009 [6].

In this paper, we took Dalian Nationalities University as an example to describe practice training details of high-quality IT information talents in ethnic higher education. For seniors of computer major, a series of experience training programs are adopted to cultivate their professional competence. For the training system, one method so-called "four-phrases, five capabilities" is adopted and one well-rounded and multiple perspective assessment approach are put forward. Here, training process includes four phrases, that is, professional quality training, professional basic theory strengthening, job skills training and job practice, which we will discuss in detail in Section III.

And our assessment system includes five parts. First, all homework or project deliverables are published online on experience training online platform for students or experts to review or peer review openly. Second, student teams can participate in the competition or write 
academic papers or apply for software copyright. If they complete these activities successfully, their grades are recorded as excellence. Third, milestone review during development process is adopted with student teams replying and directors reviewing. Fourth, professional knowledge online test is adopted. Fifth, technical discussion in replying process is also considered as part of assessment. Students can give different solutions for different technical problems. We will discuss in detail in Section IV. And Section V will conclude characteristics of our experience training program and give training results of recent three years and Section VI summarizes the paper.

\section{AdVANTAGES OF MinORITY IT TALENTS CUltivation IN DALIAN NATIONALITIES UNIVERSITY}

To safeguard national unification, social stability, cultural prosperity, social harmony and achieve common prosperity for all ethnic groups, China has made increasing efforts and carried out several significant measures to quicken the advance of the ethnic minorities and minority areas. For ethnic higher education, there are six nationalities universities under the direct jurisdiction of the State Ethnic Affairs Commission (SEAC), which plays an important role in cultivation of minority IT talents. Other five nationalities universities, such as Northwest University for Nationalities locate in northwest of China or South-Center University for Nationalities locate in southwest of China. Restricted to limit of education resources and development of software industry, they only set up professional practice courses to cultivate students with computer major. After practice training, they can hardly provide opportunities for students to participate in software company internship.

As the only nationalities university located in the northeast and coastal regions of China, Dalian Nationalities University is strong in the disciplines of engineering and applied subjects [7]. Standing on a new start line, our university aims to faithfully carry out the education guiding principle and ethnic group policies made by the Communist Party, stick to the goal of serving ethnic groups and the ethnic minority regions, lay solid foundation, optimize structure, improve connotation and outstand characteristics of college education, so as to make greater contribution to the development of ethnic groups and their regional economy, improve teaching quality and school running efficiency, enhance DLNU's comprehensive competitive edge, make DLNU an excel and dynamic ethnic university approved by people.

There are about 13,859 registered students $(13,589$ undergraduate students, 240 preparatory students, 100 graduate students) and 161 joint-program graduates. $60 \%$ percent of the students are from ethnic groups, and over $80 \%$ of the students come from ethnic minority regions and western parts of China, which is shown in Fig.1.

There are 14 classes in each year of recruit students with totally about 1630 students in college of computer science and engineering. And there are 3 undergraduate majors including computer science and technology, software engineering and network engineering. Experience training programs are set up as selective courses for senior undergraduates of three majors. Similar to students' distribution in our university, minority students and students coming from minority regions or western regions sum up over $80 \%$ of all students belonging to college of computer science and engineering, which is shown in Fig.2.

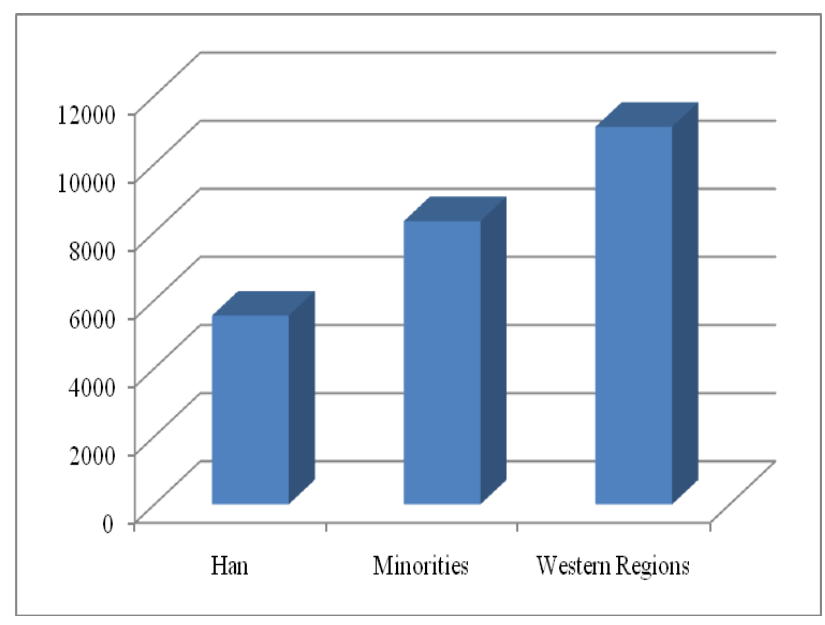

Fig 1 Students distribution in Dalian Nationalities University

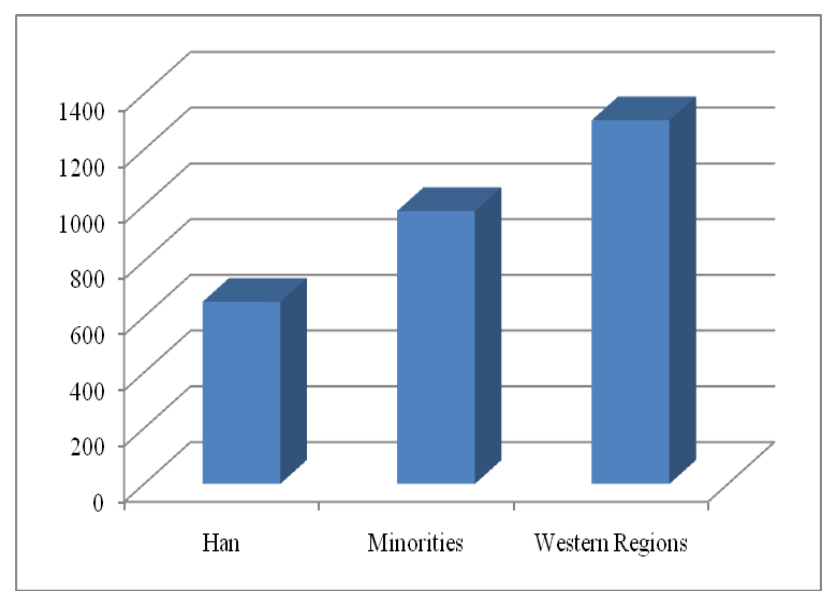

Fig 2. Students distribution in College of Computer Science and Engineering

Honored as "Hong Kong in the northern China", Dalian holds a critical position in the Northeast Asia Economic Zone and the Bohai Economic Circle, neighboring the Far East regions of Japan, South Korea, DPRK and Russia [8]. In recent years, Dalian has deepened the software export to Japan and expanded the European and the US software outsourcing market, trying hard to strengthen the development and application of BPO, ITO, KPO, embedded software and software with independent property right. In addition, digital industry and IT talents education and training have been pushed to a new height, aiming to build Dalian into the training center for China's outsourcing talents and service outsourcing center in Northeast Asia.

As reasons mentioned above, our university has unique advantage to cultivate IT minority talents based on students' distribution and geographical position. 


\section{FOUR-PHRASES, FIVE-CAPABILITIES TRAINING METHOD}

We concluded our training methods as four-phrases, five-capabilities training method.

\section{A. Four-phases, Five-capabilities Training Method}

Experience training process includes four phrases centering on capabilities cultivation. The first phrase is professional quality training, which is shown in Fig.3.

Students are trained to be proficient in necessary qualities requisite to be a software engineer by adopting various means of training such as lectures, view and emulate, zero distance activities, sincere dialogue and team competitions. For example, to integrate the graduates into society, students are trained by strengthening behavior training. And working practice in software companies help students to understand working process and be familiar with professional qualities requisite to be a software engineer. In addition, daily reports, team meetings and internship report discussions help students to manage themselves and demonstrate themselves with optimistic and confident attitudes. This professional training process can be extended to professional skills training after students have changing their roles from students to engineers. With similar training steps except technical seminars and work practice, students can complete professional skills training.

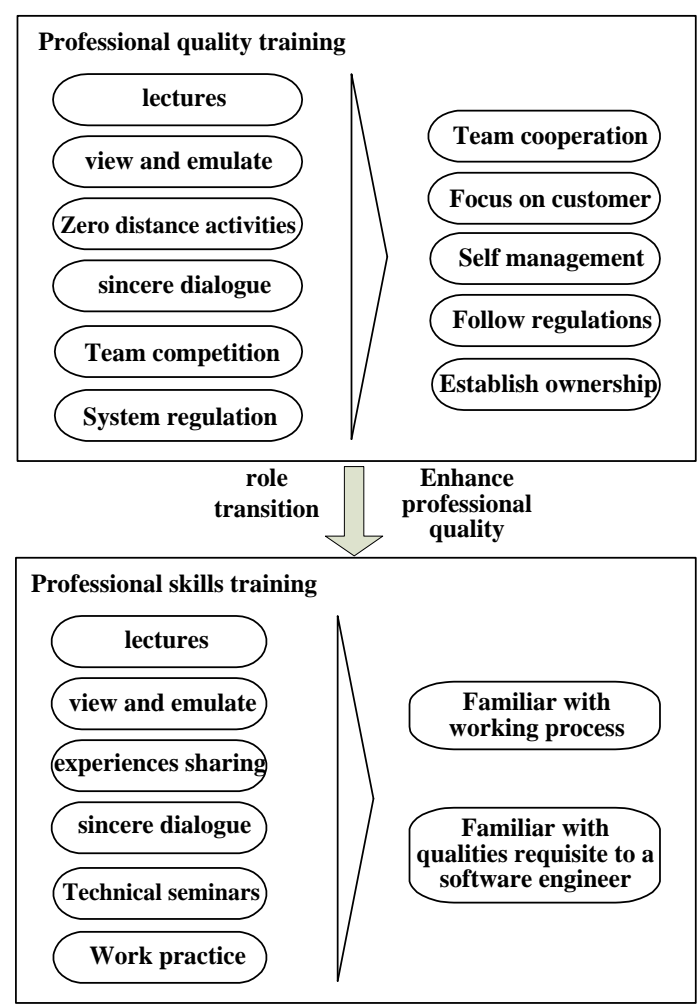

Fig 3. Professional quality training process and its subsequent skills training

The other three phrases are shown in Fig.4. The second phrase is professional basic theory strengthening. For different technical directions, tutors will present synopsis explanation of fundamental knowledge needed in work. The purpose is to help students be proficient in software development and test.

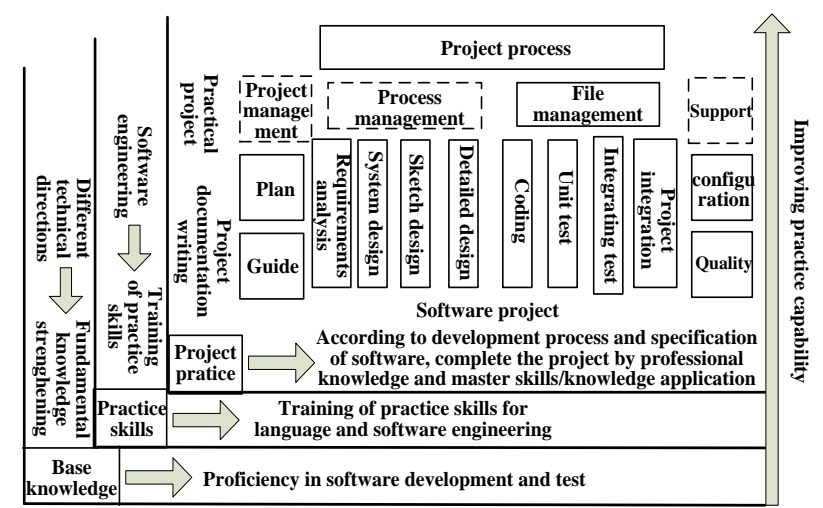

Fig 4. Training method of four-phases and five-capabilities adopted in our training programs

The third phrase is job skills training. By various kinds of activities, students can be familiar with working process in software companies and be familiar qualities requisite to be a software engineer. In this phrase, students are trained to improve their capabilities of software engineering, software fundamentals, language proficiency and project practice.

The fourth phrase is job practice. Followed by SEI (Software Engineering Institute) CMMI5 (Capability Maturity Model Integration5) standard [9], students are trained to complete work practice step by step such as requirements analysis, system design, sketch design, detailed design, coding, unit test, integration test and project integration. This process includes project management, configuration management, process management and documentation management. Whether project documentation writing or process management, all processes are strict adherence to the standards, with purpose of not only focusing on improving practice skills but also cultivating all round professional talents.

\section{B. Different Views of Experience Training Programs}

Key education purpose of our nationalities university is to cultivate professional talents for various industries and promote employment rates for the undergraduates, especially encouraging excellent graduates to working in minorities regions to contribute their efforts for minority economic development. For computer science major, experience training programs of different technical directions play very important role in cultivation minority IT talents because $80 \%$ undergraduates come from minority regions. We have set experienced training program course as the elective course for the undergraduates with computer science as major since 2009. By practice and reform year by year, we investigated one feasible scheme and teaching methods [10].

These training programs can be reviewed from two perspectives. From different perspective of participants, the programs can be shown in Fig.5. 


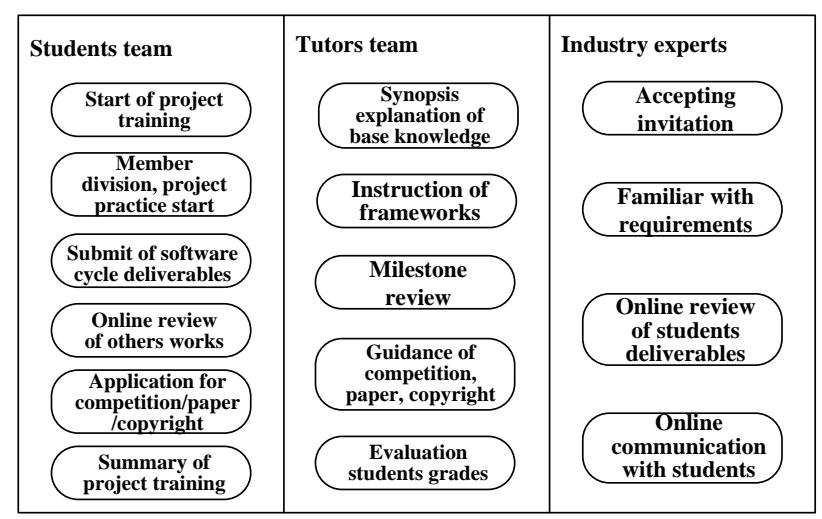

Fig 5. Running diagram of experience training program by role

There are three kinds of participants. Students team is the pricipal. From start of project training to summary of project training, students teams are requested to complete member division, submmission of software cycle deliverables step by step. Besides, they can review works of other teams online and apply for appropriate competition, write academic papers or apply for software copyrights. Tutors team is also important. At the beginning of training, they should present synopsis explanation of base professional knowledge and give instruction of popular frameworks. During process of training, they need to guide students to comlete the training and supervise their progress and quality. For example, tutors work as industry experts to review deliverables of students in each milestone. By combining all feedback grades colleted from mutual-evaluation and experts evaluation, tutors can give fair and acceptable grades for students. Industry experts, here, refers to excellent alumnies working in related industries. Besides reviewing students works, they are good examples for undergraduates to be confident in themselves and be in hopeful in future.

From time running perspective, the training programs can be shown in Fig.6.

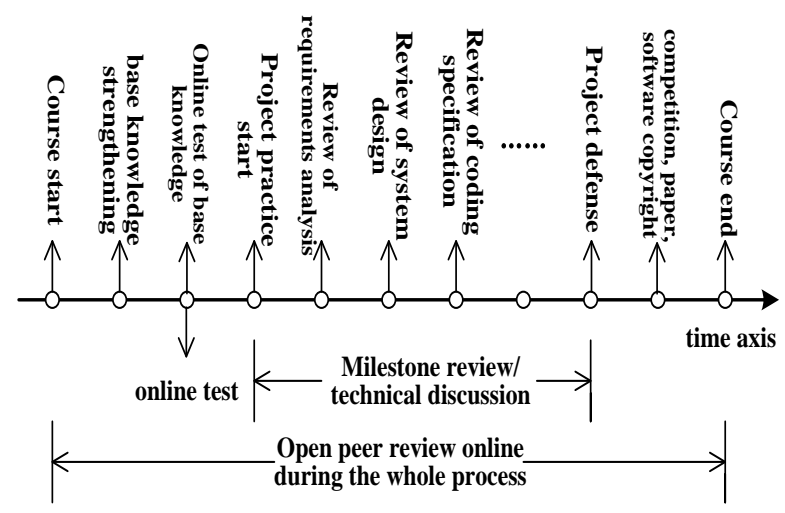

Fig 6. Activity diagram based on time axis

At each key time point, we list key activity. For exmaple, online test is finished when studetns have strengthened their fundamental knowldeg. When project practice start, milestone review and techinical discussion will continue until time point of project defense. During the whole time axis, peer review online is open for students team, tutors team or industry experts. Online learning and online test of our online teaching platform is shown in Fig.7.

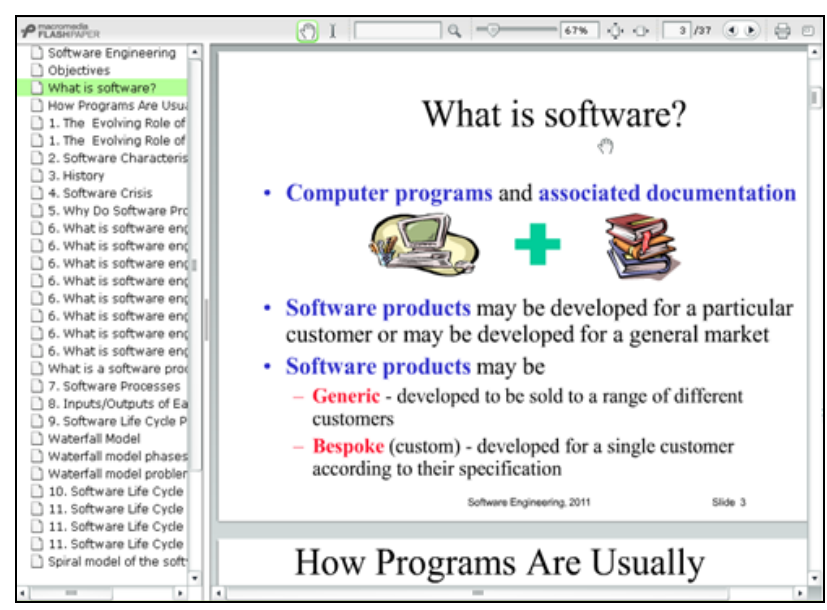

Fig 7. Online learning GUI interface

\section{ASSESSMENT METHOD}

To solve the problem of simple assessment methods with milestone review and technical test in Java experience training program, one well-rounded and multiple perspective assessment method is put forward for our experience training programs. We have adopted this evaluation system in teaching process of the training course in 2012 and 2013 [11]. To evaluate study results and teaching effect fairly with full ranges, this assessment system includes five parts.

First, all homework or project deliverables are published online on experience training online platform for students or experts to review or peer review openly [12]. By purchased Neusoft online training platform, students teams can submit their deliverables of each phrase in software lifecycle. Then all students, tutors and industry experts can browse these works and give their evaluation results. This kind of open peer reviewing and open experts reviewing help students to try their best to finish each deliverable, initiating their motivations of self-study. Because of open reviewing, few students will copy codes of others directly or copy online documents directly. Below self-respect drive, members of each students team will cooperate with each other to complete the whole development of the training program. Especially communication online or offline with excellent graduates of the same university and the same major, students will bulid self-confidence in themselves optimistically. Working experiences and achivements of these excellent graduates will not only encourag students to put much efforts on study, but also manifest their potentialities of studying.

Second, student teams can participate in the competition or write academic papers or apply for software copyright. Apply successfully what studetns have learned in the training program is our final 
objective. There are many kinds of competions at home and abroad for college studetns. Students team can choose appropriate competion such as Challenge Cup of Liaoning province to submit their software for prize. If some students are good at writing academic papers in Chinese or in English, tutors will guide them to finish one academic paper and submit the paper to some academic journal. If students complete coding of their software all by themselves, they can also apply for software copyright from National Copyright Administration. If they complete these activities successfully, their grades are recorded as excellence. One design result of class diagram applying for software copyright is shown in Fig.8, extracting from our website [13].

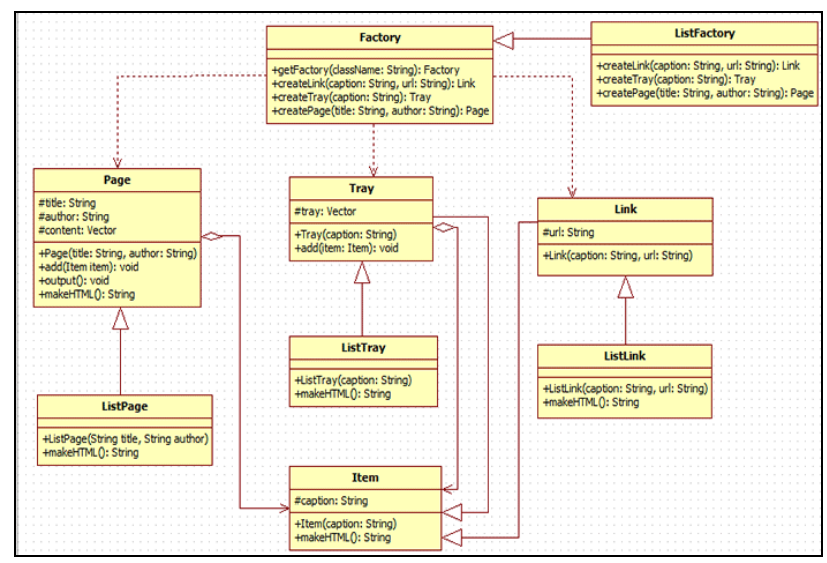

Figure 8. Class design diagram of one team

Third, milestone review during development process is adopted with student teams replying and directors reviewing. For different stages of software lifecycle of the whole training process [14], we adopt peer review as the evaluation approach referenced by many software companies, which we have discussed in detail in [15]. The review process is as follows. Team leader of each group needs to present their deliverables in Chinese or in English and answer all questions or ambiguity for the deliverables. Then tutors team decides whether the achievements is qualified. If the review is not passed, students have to modify their deliverables and repeat the review process. If the review is passed, students can go to the next step of the training process. For example, students will deliver sketch design specification after they finished requirements analysis and system design.

Fourth, professional knowledge online test is adopted. There are some basic professional theory for students to master as the entrance to software companies. Online test is the most simple and feasible evaluation method. We select some choice questions or check questions and publish the test paper online to verify whether the students have mastered the knowledge. If most of students do well in the test, tutors will continue the next training step. If many students have problems in basic knowledge, tutors will spend time teaching some key technical difficulties in detail before the next step. Online test of our online teaching platform is shown in Fig.9.

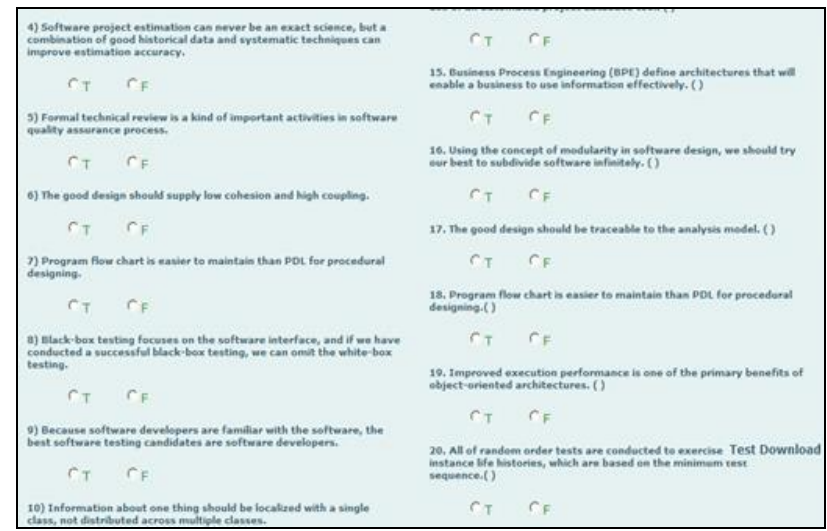

Fig 9. Online test GUI interface

Fifth, technical discussion in replying process is also considered as one assessment means. There are many technical problems existing in project review process or project defense process. It is a good idea to adopt brainstorm method to encourage students to discuss the solutions. Students can give different solutions for different technical problems. If the solutions are technical feasible, tutors can give points as part of peacetime achievements. This will help students to think the problems in deep and improve capabilities of solving problems.

This assessment method breaks through the knowledge barrier and put emphasis on competence assessment, which improves teaching quality for experience training program and assesses learning effects objectively and fairly for teaching process. Adopting this assessment method will result in inspiring students' passion for learning and helping them to build employment challenge self-confidence with optimistic and positive attitudes.

\section{CHARACTERISTICS OF OUR EXPERIENCE TRAINING PROGRAM AND TRAINING RESULT}

\section{A. Characteristics of the Experience Training Programs}

\section{(1) Cultivation mode of project + talents}

Based on the practical talents requirement of minorities and minority regions, we chose experts from different disciplines and practice fileds as tutors. Learning by doing, project based or problem based teaching mode is adopted to cultivate application talents.

Moreover, we have established joint training base with some famous companies such as Inner Mongolia Menksoft Software CO., Ltd. [16], Dalian Twin-D Port Hi-Tech CO., Ltd., Dalian Hairong Technology Development Co., Ltd. [17] and Dandong Haihua Application Technology Development Co., Ltd [18]. These Industry-Academy-Research cooperations meets practical cultivation requirments of our graduates. Faculty members in both universities and software companies have collaborated to manage and mentor the experience training programs, submit proposals, advise graduate students and publish papers. The outcome 
exhibits that the collaboration between the minority universities and high-tech information enterprises serves as a pathway for the minority university to build competencies in information industry, and bridged the widening "information gap" between majority regions and minority regions.

(2) Evaluation diversity, evaluation content all sides and evaluation all time

Integrating academic knowledge evaluation and professional competence assessment, our evaluation system consists of coding, competition, discussion and mutual-online peer review, achievement exhibition to complete diversity, all sides and all time of the evaluation. Various assessment methods have discussed in detail in the previous section. Here, multiple perspectives not only refer to extensive participation of the evaluation including tutors, students, other students, industry experts, tutor teams, but also refer to break through barrier of knowledge evaluation, focusing on professional competence evaluation including innovation ability, practice ability, communication and expression ability and team cooperation ability.

(3) Teaching open, stimulating independent innovation starting from the students interest

Tutors guide students to participate in development of practical project directly, extending traditional closed classes to open classes orienting the development of software industry. This also helps to expand the teaching scenes and reduce the gap between university and enterprises of minority information. Teaching activities are gradually moving towards standardization and specialization, developing comprehensive quality of the students.

\section{B. Training Results}

Our experience training program started from September, 2009 and have set up five teaching classes up to now. There are over 200 graduates with computer science major benifiting from the training programs. And training programs develped from only Java techinical direction to embedded development, .Net and electronic commerce.

Employment quality improves year by year. Many graduates have earned good evaluation from employers and become very capable persons. Over $80 \%$ of graduates entered well-known software companies in minority regions such as Jinlin, Xinjiang and Yunna provinces. Detailed data is shown in Table I.

Aimed at confronting some of the problems that many of the ethnic minority students from minority regions now face in trying to find employment without working experience or language abilities, we solved the problems by experience training programs. And statistical data collecting from department of enrollment and employment of our university shows minority students prefer to work in their hometowns. Familiar with life style and traditional local customs, at least over $80 \%$ minority students will go back to work in areas where minority peoples live in compact communities.

Statistical data in 2013 is not complete because this undergraduates will graduate in June of next year. So some students havent finished signing employment agreements. As shown in Table I, employment rates after training is obviously higher than employment rates of undergraduates in the same year. And acceptance rates of well-known companies in minority regions after training is higher than acceptance rates of well-known companies in minority regions for undergraduates of the same year. Also average salary level after training $(\mathrm{RMB})$ is higher than average salary level of undergraduates in the same year (RMB). Minority graduates will choose to work in minority regions after three to five years working experiences in big cities such as Beijing if not the graduation year.

Table 1. Training Data in Recent Three Years

\begin{tabular}{|c|c|c|c|}
\hline Criteria & 2011 & 2012 & 2013 \\
\hline \# students & 60 & 80 & 100 \\
\hline total \# students & 400 & 415 & 418 \\
\hline $\begin{array}{l}\text { employment rates after } \\
\text { training }\end{array}$ & $\begin{array}{c}100 \\
\%\end{array}$ & $\begin{array}{c}100 \\
\%\end{array}$ & $86 \%$ \\
\hline $\begin{array}{c}\text { employment rates of } \\
\text { undergraduates in the same } \\
\text { year }\end{array}$ & $90 \%$ & $95 \%$ & $75 \%$ \\
\hline $\begin{array}{l}\text { acceptance rates of well- } \\
\text { known companies in minority } \\
\text { regions after training }\end{array}$ & $95 \%$ & $98 \%$ & $95 \%$ \\
\hline $\begin{array}{l}\text { acceptance rates of well- } \\
\text { known companies in minority } \\
\text { regions for undergraduates of } \\
\text { the same year }\end{array}$ & $72 \%$ & $83 \%$ & $66 \%$ \\
\hline $\begin{array}{c}\text { average salary level after } \\
\text { training }(\mathrm{RMB})\end{array}$ & $\begin{array}{c}2000 \\
- \\
3000\end{array}$ & $\begin{array}{c}3500 \\
- \\
4000\end{array}$ & $\begin{array}{c}5000 \\
- \\
1000 \\
0\end{array}$ \\
\hline $\begin{array}{c}\text { average salary level of } \\
\text { undergraduates in the same } \\
\text { year (RMB) }\end{array}$ & $\begin{array}{c}1500 \\
- \\
2500\end{array}$ & $\begin{array}{c}2000 \\
- \\
3500\end{array}$ & $\begin{array}{c}2500 \\
- \\
7000\end{array}$ \\
\hline $\begin{array}{l}\text { average rates of working in } \\
\text { minority regions }\end{array}$ & $82 \%$ & $80 \%$ & $78 \%$ \\
\hline
\end{tabular}


Training data for tutors is shown in in Table II.

Table 2. Training Data For Tutors in Recent Three Years

\begin{tabular}{|c|c|c|c|}
\hline & 2011 & 2012 & 2013 \\
\hline $\begin{array}{c}\text { \# of } \\
\text { training } \\
\text { tutors }\end{array}$ & 15 & 30 & 20 \\
\hline $\begin{array}{l}\text { softwar } \\
\text { e } \\
\text { compan } \\
\text { ies }\end{array}$ & $\begin{array}{c}\text { Dalian } \\
\text { Yongjia } \\
\text { Electronic } \\
\text { Technique } \\
\text { Co., Ltd. }\end{array}$ & $\begin{array}{c}\text { China } \\
\text { national } \\
\text { software \& } \\
\text { service Co., } \\
\text { Ltd. }\end{array}$ & $\begin{array}{l}\text { Neusoft } \\
\text { Corporation }\end{array}$ \\
\hline $\begin{array}{l}\text { training } \\
\text { cycle }\end{array}$ & $\begin{array}{l}\text { three } \\
\text { weeks }\end{array}$ & four weeks & four weeks \\
\hline $\begin{array}{c}\text { training } \\
\text { content } \\
\mathrm{S}\end{array}$ & $\begin{array}{l}\text { developin } \\
\text { g cases of } \\
\text { practical } \\
\text { projects }\end{array}$ & $\begin{array}{c}\text { system } \\
\text { frameworks, } \\
\text { software } \\
\text { developmen } \\
\mathrm{t} \\
\end{array}$ & $\begin{array}{c}\text { design patters, } \\
\text { popular } \\
\text { frameworks }\end{array}$ \\
\hline
\end{tabular}

As shown in Table II, tutor teams improve project developing experiencs by training program of wellknown software companies. If a teacher wants to be a guide tutor in our experience training programs, he or she has to partipate in engineering training of popular software companies. After training in software companies, tutors accumulated engineering experiences and project management experiences, which they will apply in teaching of the training, winning wide acceptance of training studetns.

\section{CONCLUSIONS}

As the only one university locating in open coastal cities of six universities under the State Ethnic Affairs Commission, Dalian Nationalities University has irreplaceable technical advantages and regional advantages. Cultivation of ethnic minorities IT talents not only requires students to master popular software development technology, but also requires students to master minority language. Computer Science \& Engineering College takes full advantage of opportunities provided by our university, and introduces excellent enterprise resources and requirements to offer intensive enterprise courses. Integrating teaching resources of our university and enterprises, senior students with computer major are trained to complete occupation training, professional foundation strengthening and job skills training. Various forms of Enterprise-and-College joint training such as cooperation between enterprise and college, enterprise customization and engineering education internationally are adopted to investigate one feasible way of cultivating minority IT talents based on experience training programming courses for nationalities universities.

\section{ACKNOWLEDGMENT}

This work was supported in part by the Educational and Scientific Planning Subject of Liaoning Province under grant no. JG13DB130.

\section{REFERENCES}

[1] S. Liu, P. Chen, "Adoption of Employment-oriented Experience Training Program to Improve Undergraduates Employment Competence", International Journal of Modern Education and Computer Science, vol.4, no.2, pp.52-58, 2012.

[2] S. Liu, X.Z. Li and L. Zuo, "Applying Bilingual Teaching on Employment-Oriented IT Experience Training Program in Nationalities Universities", Theory and Practice in Language Studies, vol.1, no.4, pp.426-431, 2011.

[3] C. Michael, "Industry-oriented software education in practice: a case study," Proceedings of 2nd China-Europe International Symposium on Software Industry-Oriented Education, Harbin, China, January 2006, pp. 78-82.

[4] C. Michael, "Experiences in industry placement-shaping the student's Mind in an industry-oriented software engineering curriculum," Acta Scientiarum Naturalium Universitatis Sunyatseni, vol. 146, no.12, pp. 83-85, 2007.

[5] L. Q. Ye, R. H. Liu, "Experience training program with level-division: practical exploration of talents training mode for normal education," Education Exploration, no. 2, pp. 62-63, 2009.

[6] Dalian Nationalities University, 2009 Teaching Outline of Dalian Nationalities University, 2009.

[7] About DNU, Dalian Nationalities University, http://www.dlnu.edu.cn/english/aboutdlnu/index.htm, 2013.

[8] Dalian, http://en.chinasourcing.org.cn/content2.jsp?id=191.

[9] CMMI, http://www.sei.cmu.edu/cmmi/, 2013.

[10] S. Liu, X. Z. Li, P. Chen, "Research on EmploymentOriented IT Experience Training Program," Computer Education, no. 9, pp. 140-143, 2010.

[11] Dalian Nationalities University, 2013 Teaching Outline of Dalian Nationalities University, 2013.

[12] Neusoft online training platform for Dalian Nationalities University, published on local network IP address at 10.203.81.3, 2013.

[13] Course website of UML and design patterns, College of Computer Science \& Engineering of Dalian Nationalities University, http://www.anyyeah.net/dlnuuml/index.html, 2013.

[14]R. S. Pressman, Software Engineering: A Practitioner's Approach, 6th edition, Boston, MA: McGraw Hill Higher Education, 2005.

[15] S. Liu, J. Yun, W. Wang, "Research on International IT Talents Cultivation Based on Enterprise Courses for Nationalities Universities", Proceedings of 2013 Annual Bolton Institute of Higher Education of Liaoning Province, Dalian, 2013.

[16] Inner Mongolia Menksoft Software CO., Ltd., http://www.menksoft.com/Default.aspx, 2013.

[17] Dalian Hairong Technology Development Co., Ltd., http://www.yibaoli.cn, 2013. 
[18] Dandong Haihua Application Technology Development Co., Ltd, http://ddhhyyjs.cn.china.cn/, 2013.

Dr. Shuang Liu is an associate professor at the College of Computer Science \& Engineering, Dalian Nationalities University, Dalian, China. For teaching, she has been focusing on theory and application of software engineering and experience training program. For research, her current research interests include intelligent information process and machine learning algorithms. She received her Ph.D degree of Traffic Information Engineering \& Control from Dalian Maritime
University in 2006. She is a member of WASE (World Association of Science Engineering).

Mr. Peng Chen is an associate professor in Computer Science at the Department of Computer Science and Technology, Dalian Neusoft University of Information. In teaching, he has been focusing on applying CDIO concepts into Computer Science Education. In research, his current interests include cloud computing and Java-based development. Mr. Chen received his Master degree in Computer Science from Liaoning ShiHua University.

How to cite this paper: Shuang Liu, Peng Chen,"Research on Cultivation of Ethnic Minorities IT Talents in Nationalities Universities", IJMECS, vol.6, no.2, pp.33-40, 2014.DOI: 10.5815/ijmecs.2014.02.05 